\title{
A VIOLA EM CONSTRUÇÃO: A AÇÃO DA TRADIÇÃO E DA CONTEMPORANEIDADE SOBRE A VIOLA DE DEZ CORDAS NO SÉCULO XXI
}

\section{THE VIOLA UNDER CONSTRUCTION: THE ACTION OF TRADITION AND CONTEMPORANEITY ON THE TEN-STRING VIOLA IN THE 2 IST CENTURY}

\author{
Renato Teixeira Almeida \\ Universidade Federal de Minas Gerais \\ caetanoviola@gmail.com \\ Flavio Barbeitas \\ Universidade Federal de Minas Gerais \\ flaviobarbeitas@ufmg.br
}

\section{Resumo}

objetivo desta comunicação é tentar compreender quais os elementos que, atualmente, se fazem presentes e atuantes para a construção da viola caipira, ou viola de dez cordas. Para tal procurou-se entender o processo de formação da tradição caipira do instrumento e como essa tradição se apresenta frente à ação dos movimentos contemporâneos e suas miscigenações, nos dias de hoje. Baseado na dissertação de mestrado defendida em 2013 pelo autor, na qual foram feitas uma avaliação histórica da viola, bem como entrevistas com nomes importantes, além da aplicação de questionário avaliativo com violeiros e amantes da viola pode-se sugerir que estas duas forças não são excludentes, mas antes se combinam para a construção da viola de dez cordas do século XXI.

Palavras-chave: viola caipira; tradição; contemporaneidade; viola de dez cordas. 


\section{Abstract}

The aim of this communication is try to understand which are the elements that, nowadays, are present and acting to the constrution of viola caipira, of ten strings guitar. For that, we try to comprehend the formation process of folk tradition of the instrument and how this tradition act within the contemporary movements and their miscegenations, nowadays. Based on master degree thesis presented on 2013 by the author, in which were made a historical evaluation of viola, interviews with important persons of the instrument, and the application of an evaluative questionnaire with viola players and lovers we can suggest that these two forces are not excludents. Instead of that, they act togheter to built the ten strigns guitar in 21 th century.

Keywords: ten strings guitar; tradition; contemporaneity.

A viola de dez cordas', como se sabe, é um instrumento que possui, no Brasil, intensa relação de significação com a cultura interiorana e rural, também chamada de caipira. Tal relação, em certa medida, remonta aos primórdios da colonização quando, no contexto da religiosidade católica ibérica, o instrumento foi utilizado pelos jesuítas na catequização de indígenas. Em Portugal, seu país de origem, a viola já se fazia presente, desde muito antes, no acompanhamento de festejos religiosos e populares, tanto nas cidades como em regiões campesinas. - contato da viola com o sertão brasileiro foi potencializado pelos bandeirantes e seus herdeiros que, instalados no interior do país, constituíram a Paulistânia - berço da cultura caipira (CÃNDIDO, 201 1; VILELA, 2011) - e prosseguiu com os tropeiros que circulavam pelo interior do país com bois, cavalos e mantimentos, além, é claro, de histórias e canções (NEPOMUCENO, 1999) que vieram fortalecer a intima relação do instrumento com o mundo caipira. Rosa Nepomuceno descreve bem a importância da viola no contexto do sertanejo antigo:

E, nessa vida estradeira não podia faltar a violinha de arame, amarrada na sela, embrulhada num pedaço de

I $\bigcirc$ instrumento é também conhecido como viola caipira, viola de pinho, viola de arame, viola nordestina, viola de fandango, viola sertaneja, viola de feira, viola brasileira, viola branca, viola pantaneira, viola campeira, viola cabocla (CORRÊA, 2002).

\section{4}


pano. Cantar era a única diversão e o combustivel moral na caminhada(...)Choravam as saudades e narravam causos nas modas de viola e cururus feitos no lombo do animal ou ao pé do fogo, à beira do caldeirão de feijão (NEPOMUCENO, 1999, p. 82).

A simbiose entre a viola e o universo cultural caipira foi de tal ordem que o instrumento se tornou o que Charles Peirce, embasado em sua teoria dos signos, define como um índice dessa cultura.

Para Peirce (conf. TURINO, 2008), um índice aponta para a contiguidade entre signo e objeto, de tal forma que a presença de um produz automaticamente o reconhecimento do outro. Essa contiguidade se estabeleceu de tal maneira que a viola passou a ser conhecida mesmo como viola caipira, numa fórmula em que o adjetivo se torna tão naturalizado que "desaparece" em benefício de um "substantivo composto". A cultura da paulistânia ${ }^{2}$ caipira toma a viola para si como sua representante legítima, presença indispensável na vida social e religiosa do camponês, onde quer que a música fosse uma necessidade.

Mas, historicamente, nem só de cultura caipira viveu a viola no Brasil. Assim como em Portugal, ela foi também bastante utilizada em práticas musicais mais urbanas - se assim podemos dizer - desde o século $\mathrm{XVI}$ até o final do século XIX, de tal forma que a viola era o cordofone mais utilizado nas vilas brasileiras, como inclusive atestam certos relatos da literatura. Por exemplo, As Denunciações de Pernambuco ${ }^{3}$, que descrevem uma comédia encenada em 1580 ou 1581, em Olinda, na qual os versos eram cantados com o acompanhamento de uma viola. No mesmo texto, um trovador acusado de execução de trovas profanas explica que elas haviam sido interpretadas ao som da viola. (TINHO$R \tilde{O} O$, 1998). A literatura cita também alguns tocadores de viola famosos e atuantes nos centros urbanos brasileiros entre os séculos XVII e XVIII, como por exemplo: Gregório de Matos, Lourenço Ribeiro, Domingos

2 Formada após o fim do ciclo das bandeiras, no século XVIII, a região denominada por Antônio Cândido de Paulistânia, se define como o local de nascedouro da cultura e do modo de vida caipira. Englobam o que hoje seria o estado de São Paulo, Minas Gerais, Coiás e o leste de Mato Grosso e Mato Grosso do sul.

3 Primeira Visitação do Santo Ofício às Partes do Brasil - Denunciações e Confissões de Pernambuco 1593-1595, $1^{10}$ ed. Conjunta, fac-simile das edições de 1929 "Denunciações de Pernambuco 1593-1959", editada por José Antônio Gonsalves de Mello, Recife, UFPE/ Fundação do Patrimônio Histórico e Artístico de Pernambuco, 1984, pp. 42-43 (Citação retirada de TINHORÃO, 1998, p. 47).

\section{5}


Caldas Barbosa. Na mesma linha, TABORDA (2004) relata que, ainda no final do século XIX, no Rio de Janeiro, a viola era usada tanto para o acompanhamento das músicas dos barbeiros (considerada pela autora como a mãe do choro), quanto dos saraus nas casas da elite carioca, ou, ainda, nas folias do Divino.

E é só então, em fins do século XIX, com a chegada da guitarra francesa - conhecida entre nós como violão ${ }^{4}$ - que a viola perde seu espaço e suas funções tanto nas casas grandes quanto nas danças populares citadinas. As razões para isso, discutidas por CISELA NOCUEIRA (2008), parecem estar relacionadas à uma procura por um "ideal republicano" e à consequente busca de novos símbolos inspirados em fontes políticas, sociais e culturais europeias, mais precisamente, francesas. Gisela relata que:

O ideal republicano, dividido, não poderia contemplar a realidade como se apresentava. Preponderante era a formação de um ideário apresentado sob forma de simbologia que o identificasse. Assim sendo, tudo o que se mostrava retrógrado ou anacrônico, inclua-se a viola, deveria, tão simplesmente, desaparecer (NOCUEIRA, 2008, p. 48).

O ideal republicano, grosso modo, levou a música brasileira da época a uma separação em dois grandes conjuntos: a música considerada séria, erudita ou clássica; e a música chula ou popular, esta subdividida em duas outras categorias: uma incorporada pela mídia da época e que, assim, recebia "permissão" social, e uma outra, praticada ainda nas ruas e principalmente no campo, que deveria desaparecer. A viola está a serviço desta última e sua utilização passa a ser estigmatizada (NOCUEIRA, 2008, p. 68). De forma muito resumida, é assim que o instrumento, antes presente na cultura do país de uma forma bem mais geral, passa à condição de pária do ideal republicano e, expulso da cidade, encontra guarida exclusiva na cultura caipira. Nesse universo, a viola associa-se cada vez mais à dimensão religiosa, incorporada nos festejos que passam a ser conduzidos pelos caboclos do interior do país, e ali mantida viva e ativa culturalmente.

$4 \bigcirc$ nome violão é originário de uma comparação com a viola quando da sua chegada no Brasil. Por ser um instrumento semelhante, mas de maiores dimensões do que a viola, recebe o nome que sugere o aumentativo desta: uma viola grande, ou seja, um violão.

\section{6}


Ao longo do século XX, num processo decorrente da própria modernidade, diminui paulatinamente a distância cultural entre o sertão e as cidades. Como resultado, as práticas musicais com a viola absorvem possibilidades novas, típicas do mundo urbano, que a deslocam, ao menos parcialmente, de seu universo simbólico rural. $\bigcirc$ nome que se apresenta como precursor desse movimento de reaproximação é Cornélio Pires que, em 1929, produz os primeiros fonogramas de duplas caipiras. Esse deslocamento do sertão para as salas de gravação é um evento de tal ordem que produzirá ao longo do tempo várias modificações no uso da viola. Uma delas, porém, é imediatamente verificável e se dá no plano simbólico: a viola é suspensa do tradicional papel na coesão sociocultural do bairro caipira para acompanhar canções que são, antes de tudo, objetos comerciais, mercadoria. Sobre isso, Ivan Vilela, citando o professor José de Souza Martins relata que "as gravações fizeram essas músicas saltarem do seu uso ritual, sagrado ou profano, para atenderem uma demanda do mercado" (VILELA, 20 I I).

No cenário contemporâneo, a viola se encontra sob a ação de duas linhas de força bem distintas: de um lado, o conjunto dos laços identitários que a vinculam à tradição caipira e reforçam os processos, usos, e relações que o instrumento tem com essa cultura; de outro, as influências modernizantes que sugerem uma ruptura com essa tradição através de demandas da produção musical ligadas ao ambiente urbano. Apesar de essas duas linhas de força já se apresentarem atuantes no contexto da viola desde a década de 1930, é a partir do início da década de 1970 que elas podem ser mais claramente percebidas. Isso é devido à entrada no contexto de um grupo de jovens, nascidos ou claramente formados no contexto urbano, que começam a se interessar pela viola caipira. Apesar de uma formação cultural tipicamente urbana, muitos com titulação acadêmica (em música ou em outras áreas) e alguns até mesmo instrumentistas premiados, a maioria descende de famílias de origem interiorana. Não podemos, assim, falar que o mundo cultural caipira lhes é de todo desconhecido. Nomes como o sul matogrossense Almir Sater, o paulistano Renato Teixeira, e os mineiros Roberto Corrêa e Paulo Freire, dentre outros, inicialmente promovem, da cidade, uma tentativa de retorno mais ou menos idealizado aos usos caipiras da viola, tentando decifrar seus segredos e toques característicos. Sobre isso, Roberto Corrêa relata que:

Eu comecei em Brasília, eu estava no curso de física,isso foi em 77. E uma das questões que surgiu foi que não havia

\section{7}

REV. TULHA, RIBEIRÃO PRETO, v. 2, n. 2, p. 63-76, jul.-dez. 2016 
método de ensino. (...) E aí eu passei a ir atrás, fui na biblioteca, na UnB, não achei nada. Aí eu passei a ir atrás dos violeiros antigos pra aprender os toques, as levadas, as afinações (Roberto Corrêa, em entrevista concedida ao autor).

Os novos violeiros, contudo, não se voltam para o mundo caipira "de malas vazias" e bastaria essa constatação para evitar a caracterização de seu movimento como um "resgate", como é comumente divulgado. Não seria, na verdade, apenas um desejo de retorno às formas tradicionais de uso da viola que os motivou, dadas, inclusive, as inúmeras divergências de contexto social, cultural, econômico e geográfico. Mais que isso, esse movimento pode ser compreendido sob o signo da procura bem moderna de novas informações estéticas, ainda que a novidade, aqui, se apresentasse nas vestes de um passado tradicional, sagrado ou até mesmo mítico. Ocorria, na verdade, a releitura de um processo cultural que era bem distinto da experiência pessoal de cada um desses jovens (ainda que pontos de contato existissem) e que acabou por dar origem a um cenário fundamentalmente novo para a viola. A resposta do violeiro Almir Sater, um dos nomes mais respeitados pela nova geração da viola e considerado, talvez, o precursor do movimento chamado de neo-caipira, ilustra muito bem esse quadro:

Eu não tenho tradição de viola caipira. Mas, assim, na minha formação de Campo Grande, de música, assim, eu sempre fui, assim... a gente saía, nos domingos pra almoçar fora, tinha aqueles conjuntos paraguaios. Dois violões, uma requinta, um contrabaixo de pau, um bandoneón, e grandes cantantes, né? E minha formação musical foi ouvindo esses caras, assim...somando mais rock'n roll, Pink Floyd, Beatles, Blues, música latinoamericana dos Andes, que eu gosto muito de charango. Eu gosto muito dessas coisas, essas misturas de sons. Minha tradição está mais por aí! Eu escutava muita viola caipira no rádio. Sintonizava em ondas curtas, antigamente lá de São Paulo e ficava escutando os velhos violeiros pontearem a viola. Eu era pequenininho e botava na cabeceira da cama e escutava, de noite, os violeiros tocando (Almir Sater, em entrevista concedida ao autor).

Independentemente do que promoveu esse movimento, o que se observa, então, é que por meio dele se concretizou um lado do processo mais amplo de expansão cultural (práticas, concepções, valores, mercantilização) da cidade em direção ao campo, com a apropriação,

\section{8}


e consequente ressignificação, de uma prática musical até aquele momento localizada mais ou menos à margem dos interesses e das dinâmicas do mercado urbano.

Após um resumo crítico da história da viola no qual se procurou demonstrar a presença e a ação dessas forças supracitadas, o objetivo que se apresenta é de tentar compreender como essas forças atuam sobre a "reinvenção" contemporânea desse "novo" instrumento que estamos designando como viola de dez cordas. Para tal, é fundamental caracterizar mais detidamente cada uma delas. Na primeira, observa-se que os laços identitários com o universo caipira determinam uma prescrição de performance para a viola, exercendo um caráter normativo e invariável que só se reforça à medida que o tempo se prolonga. Criase, então, uma tradição caipira da viola em moldes que poderíamos basear na abordagem de Hobsbawn E Ranger ( 1997) que consideram o estabelecimento de uma relação de continuidade com um passado uma importante característica para a formação ou invenção de qualquer tradição.

Nesse contexto, podemos pensar que a relação da viola com a sua tradição caipira é que the dá o caráter de autenticidade que rapidamente se transmuta em poder. A presença e a sonoridade da viola fazem o ouvinte estabelecer uma conexão simbólica com a cultura caipira. A frase "A viola carrega o sertão dentro do seu bojo", tão repetida por grande parte dos violeiros, encontra aí seu fundamento.

Todavia, a trajetória da viola, quando confrontada tanto com um passado mais remoto, de acordo com o que foi brevemente demonstrado anteriormente, quanto com o presente exibe um cenário mais conflituoso do que faz crer o relato mais plano da tradição. No caso do presente, se a história cultural se resumisse a um jogo de causas e efeitos, seria possivel até supor que as influências urbanas que promoveram modificações profundas no uso da viola teriam o poder de solapar completamente as práticas tradicionais anteriores, com uma total desfiguração do instrumento. É óbvio que as coisas não se dão dessa maneira. Em termos culturais, e o que se observa é que as inovações não só não eliminam as relações tradicionais, como muitas vezes as reforçam.

De acordo com Handler e Linnekin, (1984, apud SANDRONI, 20 I I) como o discurso que enuncia a tradição é construido num presente, a problemática que envolve uma herança pura requer reflexão: 
As tradições não são autênticas nem espúrias, pois se por "autênticas", entendermos uma herança pura e imutável do passado, então todas as tradições autênticas são espúrias; mas, se (...) a tradição é sempre definida no presente segue-se que todas as tradições espúrias são autênticas (HANDLER \& LINNEKIN, 1984, p. 273; apud SANDRONI, 2011, p. 103).

A definição de Handler e Linnekin (1984), de certa forma, fundamenta a força da tradição caipira que a viola adquiriu após o estabelecimento de suas funções nos bairros caipiras, como já descrito, mas não a partir de uma relação pura e exclusiva com esse contexto. A viola se tornou caipira já devido a modificações de seus outros usos, originários de Portugal, em um tempo histórico anterior. Isso permite considerar que a viola se fez caipira através de ressignificações de práticas ainda mais antigas. Nada de substancialmente revelador aqui: a cultura é mesmo um processo de trocas contínuas e incessantes que se estabiliza apenas em narrativas. É preciso, então, flagrar momentos decisivos em que as práticas culturais tomam a forma de relatos e geram a rede simbólica correspondente, não necessariamente para desconstruí-los, mas para, historicizando-os, inibir posturas excessivamente reativas. Assim, evidenciar que a tradição caipira é já uma ressignificação de práticas preexistentes não diminui em nada sua importância ou seu prestígio, nem a torna uma tradição espúria em sentido depreciativo. Antes, reforça a sua autenticidade no sentido dado por Handler e Linnekin.

Na verdade, esse movimento de manutenção e de modificação dos usos e funções socioculturais da viola de dez cordas parece ser inerente e estar constantemente presente na história do instrumento. Podemos compreender esse movimento por diretrizes teóricas inspiradas no que Deleuze \& Guattari ( 1997) definem como "fenômeno de borda". Em certo momento identifica-se o desejo pela manutenção das identidades que constituem determinado objeto - a viola, no nosso estudo. As forças ligadas à identidade criam um centro de manutenção de usos e funções que, por consequência, afasta o objeto da periferia, da fronteira, do local onde se encontram as possibilidades de troca e de modificação desta. No entanto, o processo prevê que, de tempos em tempos, surjam, produzidas internamente ou vindas de fora, forças ou pulsões que visam o distanciamento do centro e portanto da manutenção do status quo, em busca das fronteiras, em busca das trocas e misturas com o "novo" e o "desconhecido". Esse distanciamento do centro é produzido pelo que os autores denominam de "feiticeiro" ou "outsider" que, ao 
ameaçar esse status quo com suas iniciativas inicialmente incômodas e desagradáveis, provoca uma inquietação que propicia as mudanças que parecem ser essenciais para a sua sobrevivência. Podemos, mesmo que sob o risco de ser tendencioso, designar os papéis das duas forças em ação no caso: de um lado, a tradição caipira da viola; de outro, o universo urbano e seu conjunto de novas demandas e práticas culturais.

As conclusões encontradas na dissertação de mestrado (ALMElDA, 2013), em que foram feitos questionários com violeiros e amantes da viola ${ }^{5}$ bem como entrevistas com nomes de grande importância para o instrumento ${ }^{6}$ sugerem que a influência urbana que se infiltra no mundo caipira da viola, com a consequente entrada de novos signos e novos usos, não tem o poder nem tampouco a intenção de apagar a prática anterior. Todas as respostas obtidas pelo questionário construido para a presente pesquisa nos direcionam para um desejo de que a viola esteja presente na maior quantidade de situações possiveis e das mais diversas formas possiveis, o que certamente não exclui seu uso, digamos, tradicional caipira. Além do questionário aplicado, alguns depoimentos colhidos entre pessoas de nome no mundo da viola atual não possui um sentido diferente das respostas obtidas. $\bigcirc$ relato do violeiro Paulo Freire de uma discussão sobre técnicas de mão direita entre ele e seu mestre Manoel de Oliveira deixa clara a tranquilidade do violeiro antigo frente a inovações:

(...) lá na casa do Seu Manoel...ele tinha um violão, e eu peguei o violão e toquei um choro. Aí ele começou a observar e falou assim: "Paulo, você toca bonito, e coisa e tal, e não sei quê". E a mão direita do violeiro lá só usa o polegar e o indicador. Aí seu Manoel falou assim: "Mas você usa os outros dedos também". Eu falei: "É Seu Manoel, eu uso os outros dedos mas, eu quero tocar viola do seu jeito, usando esses dois dedos, com o indicador que sobe e desce, como se fosse uma palheta". Tem um suinge ali, um molho que vai nesses dois dedos. E Seu Manoel falou assim: "Você tá muito certo. Você toca igual eu com os dois dedos. Mas usa os outros que você também sabe usar" (...). E o meu caminho

5 Foram feitos, para a dissertação, questionários normatizados aplicados em duas situações: no seminário "Voa Viola", que aconteceu em Belo Horizonte, entre os dias II e 13 de maio de 2012 e na "Roda de Viola do Mercado Novo". Conhecido ponto de encontro de violeiros caipiras em Belo Horizonte.

6 Foram entrevistados para a dissertação os violeiros, Roberto Corrêa, Almir Sater, Badia Medeiros e Paulo Freire e a produtora cultural Myriam Taubkin.

\section{1}

REV. TULHA, RIBEIRÃO PRETO, v. 2, n. 2, p. 63-76, jul.-dez. 2016 
era usar os outros dedos, quer dizer, era usar o que eu tinha aprendido de Bossa Nova, de choro, de improvisação, de jazz (Paulo Freire, em depoimento dado ao autor).

Em entrevista para a revista Viola Caipira, o mestre Cedeão da Viola?, falecido em 27/07/2005, ao ser perguntado sobre o uso da viola em outras situações, conduz sua resposta na mesma direção:

Quem manda é quem está tocando e eu dou força pros meus alunos fazer isso. Eu normalmente ensino música caipira e música paraguaia, que é o meu estilo. Mas eu dou força para os meus alunos tocar qualquer tipo de música: internacional e brasileira. Na minha época a música internacional era a paraguaia e mexicana; hoje é americana e europeia (Revista Viola Caipira vol. 12, p. 33).

Parece que, realmente, numa chave de interpretação marcada pelas diretrizes de um mercado de signos globalizado, os sujeitos da pesquisa aceitam e incorporam recursos técnicos e estéticos de diferentes origens, caipiras ou urbanas, nacionais ou estrangeiras, para "colorir" suas performances atuais.

Podemos, então, afirmar, apoiado nas pesquisas para a dissertação de mestrado (ALMEIDA, 2013) que o desejo da grande maioria dos amantes da viola não é a separação dela do seu uso antigo e de suas aplicações e significações tradicionais, pelo menos as relacionadas ao mundo caipira. Em todas as respostas do questionário, a importância da manutenção da viola como índice caipira foi considerada, no mínimo, quase tão importante quanto a sua miscigenação com o contemporâneo. E essa é a mesma opinião de vários nomes importantes, principalmente os relacionados ao movimento neo-caipira. $\bigcirc$ violeiro Roberto Corrêa diz da importância do conhecimento dos toques tradicionais:

Então, (a viola) é um instrumento que tem uma tradição e que não chegou completa n'agente porque não era obra escrita. Então você veja a importância desses toques que os violeiros nos trazem, porque são reminiscências de centenas de anos atrás. Então, primeiramente agente tem que

7 Gedeão da Viola (1945-2005) acompanhou, durante 16 anos, o violeiro Tião Carreiro e também Téo Azevedo, fazendo afinações na viola e participando de gravações. foi considerado no início dos anos 2000 como um dos quatro melhores violeiros do Brasil, além de ser o principal tocador de viola autêntica. (http://www.dicionariompb.com.br/ gedeao-da-viola) 
cultuar esses toque. (Roberto Corrêa em depoimento dado ao autor).

O violeiro Paulo Freire segue no mesmo sentido de valorização da tradição caipira da viola.

É super importante ir lá pro Urucuia, encostar no Seu Manoel, encostar no Seu Badia, qualquer mestre desses e aproveitar o máximo deles, que não deixa de ser uma escola. Eu vou estudar viola erudito em Paris, mas eu vou estudar viola no sertão do Urucuia. Eu acho a mesma coisa (Paulo Freire, em depoimento dado ao autor).

Esse excerto do depoimento do violeiro Paulo Freire pode nos dar uma pista de como essas duas forças se relacionam, na realidade. $\bigcirc$ que parece transparecer é que essas linhas de pensamente com relação à viola - o desejo pela manutenção da tradição e a vontade de novos "usos" para o instrumento - apesar de aparentemente antagônicas, são, na verdade, complementares. Como um ciclo de criação, manutenção e destruição, podemos dizer inclusive, que a existência de uma é responsável pela manutenção da outra. Podemos dizer que uma tradição só permanece forte se, ao mesmo tempo em que é mantida em seu cerne, ela passa por modificações e adaptações no decorrer dos anos e das gerações.

Podemos sugerir uma compreensão dessas relações sob a luz de outro conceito criado pelos autores DELEUZE \& CUATTARI (1997), o conceito de ritornello. Os autores descrevem esse conceito através de 3 situações-exemplo: 1- uma criança canta no escuro para espantar o medo. Esse canto cria um centro de conforto, de calma, um status quo que promove a formação de um centro calmo e estável promotor de segurança e estabilidade. 2- Uma mulher liga o rádio enquanto realiza as tarefas domésticas ou uma música é cantada a plenos pulmões para dar sentido a uma comemoração. Isto produz uma delimitação de um espaço, é traçado um círculo em torno do centro e determinado um limite para esse espaço que, então se separa do todo. 3- Esse círculo formado é aberto, quebrado, por onde as forças escapam e se misturam à forças que estavam antes fora dele. Ainda de acordo com DELEUZE \& CUATTARI (1997), essas três situações-exemplo não podem ser entendidas como "três movimentos em evolução, mas como três aspectos numa só e mesma coisa: o ritornello". 
O conceito de ritornello define, então, que um "meio" ou um "território" (a viola, no nosso caso) se mantém às custas de movimentos de territorialização e desterritorialização de si mesmo, isto é, de construção, desconstrução e reconstrução de sua identidade, e assim por diante. Entretanto, não podemos falar que essa desconstrução seja de tal vulto que promova uma destruição completa desta. Se assim fosse, teríamos, a cada reconstrução, um instrumento diferente e totalmente separado do seu uso anterior. A cada movimento de ritornello algo permanece e vai, com o tempo, construindo uma imagem que forma o instrumento, no nosso caso, a viola de dez cordas. A reconstrução histórica da viola feita no presente trabalho deixa bastante claro esse movimento.

Podemos sugerir, então que, o instrumento que atualmente é chamado de viola de dez cordas é o resultado das várias situações históricas de tradições nas quais ele esteve inserido e de posteriores deslocamentos para uma nova função e consequente formação de uma nova tradição e assim por diante. Tanto a prática da tradição quanto os "novos usos" são importantes e agem em conjunto, cada um a seu tempo, para que a viola de dez cordas seja mantida viva e atuando no decorrer dos anos. Podemos dizer que ela passa, no momento atual, por uma expansão de suas possibilidades causada pela valorização das miscigenações promovidas pelas relações urbanas e pelo mundo contemporâneo. Mas, a história nos mostra que o que, hoje, é considerado novidade pode, futuramente, ser entendido como uma nova tradição da viola de dez cordas. 


\section{Referências}

ALMEIDA, Renato Teixeira. Viola de Dez Cordas - Entre a Tradição e a Contemporaneidade. 2013. Dissertação. Escola de Música da UFMC, Belo Horizonte.

CÂNDIDO, Antonio. Os Parceiros do Rio Bonito. $11^{1} \mathrm{Ed}$. Rio de Janeiro: Ed.Ouro sobre azul, 2011.

CORREAA, Roberto. a Arte de Pontear a Viola. $1^{\circ}$ Ed. Brasilia: Ed. Viola Corrêa, 2002.

DELEUZE, Giles. E CUATTARI, Felix. Mil Platôs - capitalismo e esquizofrenia, vol. 4. Ed. 34, 1997.

HOBSBAWM, E \& RANCER, T. A Invenção das Tradições. São Paulo: Ed. Paz e Terra, 1997.

NEPOMUCENO, Rosa. Música Caipira - Da Roça ao Rodeio. $1^{10}$ Ed. São Paulo: Ed. 34, 1999.

NOGUEIRA, Gisela Pereira. A viola com anima: uma construção simbólica. 2008. Tese. USP, São Paulo.

LEMOS, Pedro. "10 anos sem Tião Carreiro". Revista Viola Caipira, vol. 4, p. 18-23, 2003.

SANDRONI, Carlos. Tradicionalidade e suas controvérsias no Maracatu de Baque-virado. In V ENABET. Belém. P. 101-107, 2011.

TABORDA, Márcia. Violão e ldentidade Nacional. $1^{\natural}$ Ed., Rio de Janeiro: Ed. Civilização Brasileira, 2011.

TINHORÃO, José Ramos. Historia Social da Música Popular Brasileira. Ed. 34, 1998.

Domingos Caldas Barbosa, O poeta da viola, da modinha e do lundu (1740-1800). Ed. 34, 2004.

VILELA, Ivan. Cantando a própria história. 2011. Tese. USP, São Paulo. 


\section{Sobre os autores}

Renato Teixeira Almeida, mestre em música pela Escola de Música da UFMC, Doutor em Ciências Biológicas pelo ICB-UFMC. Tem seu interesse direcionado especialmente para os estudos a viola de dez cordas, conhecida como viola caipira, seja no seu contexto histórico, relacionado à construção e formação da cultura caipira, seja nas suas atuais relações com o mundo contemporâneo. Atua como professor de viola desde 2002 e foi, durante seu mestrado, responsável pela disciplina optativa "viola de dez cordas" na graduação da Escola de Música da UFMC.

Flavio Barbeitas é violonista, natural do Rio de Janeiro, Flavio Barbeitas é Bacharel e Mestre em Música pela UFRJ, Doutor em Estudos Literários pela UFMG/ Universidade de Bologna (Itália) e Pós-doutor em Musicologia pela Universidade Nova de Lisboa. Desde 1996, atua como professor de violão e de disciplinas musicológicas na Escola de Música da UFMG nos níveis de graduação e pós-graduação. Paralelamente às atividades didáticas e artísticas, tem especial interesse teórico pela relação da música com a literatura/linguagem e com a cultura brasileira de um modo geral. Na UFMC, lidera o Núcleo de Estudos em Música Brasileira (NeMuB) e participa dos grupos de pesquisa Resgate da canção brasileira, dedicado ao gênero "canção de câmara", e Intermídia, ao lado de professores e artistas ligados às áreas de Literatura e Artes Cênicas.

Recebido em: 10/09/2016

Aprovado em: 16/12/2016 